\title{
Impact of ferritin serum concentration on survival in children with acute leukemia: a long-term follow-up
}

\author{
Monika Łęcka*, Krzysztof Czyżewski, Robert Dębski, Mariusz Wysocki, Jan Styczyński \\ Department of Paediatric Haematology and Oncology, Collegium Medicum, Nicolaus Copernicus University Toruń, \\ Jurasz University Hospital 1, Bydgoszcz, Poland
}

\begin{abstract}
Introduction: Nowadays, a significant number of children with acute leukemia can be cured. Iron overload, related to blood transfusions and its long-term complications, remains a problem. Elevated ferritin concentration is often observed in this group.

The aim of this study was to evaluate the prognostic value of serum ferritin on long-term outcomes in children treated for acute leukemia.

Material: We studied 71 patients treated for acute lymphoblastic (ALL) or myeloblastic (AML) leukemia between 2005 and 2011. Serum ferritin concentration, serum transaminases activity, lactic dehydrogenase and C-reactive protein levels (CRP) were analysed. Serum ferritin $>1,000 \mu \mathrm{g} / \mathrm{L}$ was considered to be a marker of iron overload.

Results: Thirty-seven patients (52.1\%) had iron overload. Ferritin serum concentration correlated with alanine aminotranferase activity $(p=0.001)$ and CRP concentration ( $p=0.012)$. A total of $19(26.76 \%)$ patients died during follow-up. Ferritin level was higher in patients with AML vs. ALL. There was a significant difference in long-term outcomes with respect to high ferritin concentrations, both in patients undergoing haematopoietic cell transplantation (HCT) and in the non-HCT group.

Conclusions: In both groups, patients with higher ferritin concentrations had worse overall and event-free survivals and a higher relapse incidence. Ferritin concentration $>1,000 \mu \mathrm{g} / \mathrm{L}$ was the strongest determinant of long-term treatment outcome. Ferritin serum concentration $>1,000 \mu \mathrm{g} / \mathrm{L}$ is an adverse prognostic marker of survival in children with acute leukemia treated with chemotherapy with or without HCT.
\end{abstract}

Key words: ferritin, iron, leukemia, children, haematopoietic cell transplantation

Acta Haematologica Polonica 2021; 52, 1: 54-60

\section{Introduction}

In recent years, a great deal of progress has been made in treating acute leukemia in children. Nonetheless, treatment is still complicated by significant morbidity and mortality. With improved diagnostic procedures, intensification of therapy, and effective treatment of infections, the prognosis for children with acute lymphoblastic leukemia (ALL) and acute myeloid leukemia (AML) has improved [1-3]. However, a major challenge has arisen regarding long-term complications including iron overload and its sequelae [4].

Serum ferritin is usually used to detect iron overload. It is a sensitive parameter, albeit of low specificity because it can be elevated in a variety of inflammatory states, as well as other clinical entities including sickle cell anaemia [5], haemophagocytic lymphohistiocytosis and macrophage activation syndrome [6]. It is also a surrogate marker for cytokine release syndrome [7] and neuroblastoma [8]. The incidence of hyperferritinemia increases with the
*Address for correspondence: Monika Łęcka, Department of Paediatric Haematology and Oncology, Collegium Medicum, Nicolaus Copernicus University, Jurasz University Hospital 1, Skłodowskiej-Curie 9, 85-094 Bydgoszcz, Poland, e-mail: lecka.monika@gmail.com
PTHiT

प्रिए
Copyright (C) 2021

The Polish Society of Haematologists and Transfusiologists,

Insitute of Haematology and Transfusion Medicine.

All rights reserved. 
number of transfusions. One red blood cell (RBC) unit administered to correct anaemia contains 200-250 mg of iron which is being delivered to the patient. Iron overload can occur after 10-20 RBC transfusions. It is universally recognised that iron overload is a risk factor for organ and metabolic complications. Dysfunction of the heart and liver are commonly observed [9].

Serum ferritin concentration has been shown to be a strong predictor of survival after allogeneic haematopoietic cell transplantation (allo-HCT) [5, 8, 10, 11]. Apart from acute leukemia patients, iron overload resulting from transfusion-dependent conditions is frequently observed in patients with myelodysplastic syndromes (MDS). In that group, elevation of serum ferritin is associated with a high risk of leukemic transformation [12].

Data regarding the impact of serum ferritin concentration on treatment in children with acute leukemia or undergoing HCT is scarce. Thus, the objective of this study was to evaluate the prognostic value of serum ferritin concentration on the long-term treatment results in children with acute leukemia who were undergoing intensive chemotherapy with or without HCT.

\section{Material}

\section{Study design}

In this retrospective single centre study, all patients treated in our department for acute leukemia between 2005 and 2011 who were tested for ferritin serum concentration were included. Children undergoing multiagent chemotherapy with or without subsequent HCT were qualified for long-term follow-up. This study was approved by the Local Bioethical Committee (169/2020; 31 March 2020).

\section{Collection of data}

Serum ferritin concentration, serum transaminases activity, and C-reactive protein (CRP) levels were analysed among the study participants. In all cases, ferritin concentration was measured at least four months after the diagnosis of leukemia. In cases of multiple testing, the highest concentration was taken into account. Serum ferritin >1,000 $\mu \mathrm{g} /$ / $L$ was considered to be a marker of iron overload. The values of CRP, alanine aminotransferase (ALT), aspartate aminotransferase (AST), and lactate dehydrogenase (LDH) obtained at closest proximity to the day of ferritin concentration testing were also analysed. In most cases, the time interval between these tests was four days or less.

\section{Treatment of leukemia}

Children with de novo ALL were treated according to the ALL-IC-2002 protocol. Children with relapsed ALL were treated according to the ALL-REZ BFM 2002 protocol. Children with de novo AML were treated according to the AML-BFM-2004 protocol. Children with relapsed
AML were treated according to the IDA-FLAG/FLAG protocol.

\section{Transplant procedures}

Children were qualified for HCT according to chemotherapy protocols. The conditioning regimen before transplantation was either myeloablative (MAC) or reduced intensity conditioning (RIC). MAC was based on total body irradiation (TBI), busulfan or treosulfan. RIC was based on fludarabine or busulfan at doses of $\leq 8 \mathrm{mg} / \mathrm{kg} /$ cycle. For prophylaxis of graft-versus-host disease (GvHD), cyclosporine A (CsA) and short-term methotrexate (MTX) were used. Patients from alternative donors [i.e. matched unrelated donor (MUD), mismatched unrelated donor (MMUD), or haploidentical donor] received anti-thymocyte globulin (ATG).

\section{Definitions}

The primary endpoint was overall survival (OS). Additional endpoints were event-free survival (EFS) and relapse incidence (RI). An event was defined as relapse or death from any cause. EFS was defined as survival without evidence of relapse or progression. Relapse was considered in the presence of $>5 \%$ bone marrow (BM) blasts and/or the reappearance of the underlying disease. OS was analysed for non-HCT patients as the time from the start of chemotherapy to death from any cause, or until the end of follow-up; OS for transplanted patients was calculated from the day of allo-HCT to death from any cause or until the end of follow-up. Death from any cause was regarded as an event for OS, while relapse and death from any cause were considered to be events for EFS. RI was estimated by considering a relapse or the reappearance of the underlying disease as events of interest, and death without relapse as a competing event.

\section{Statistical analysis}

The Mann-Whitney U-test was used for non-categorical comparisons and Chi-square or Fisher exact test for categorical comparisons. Correlations between laboratory parameters were analysed with Spearman rho coefficient. OS, EFS and RI were calculated with the Kaplan-Meier curves method, and differences between the curves were compared by log-rank test. Mean survival was determined by Kaplan-Meier method. The Cox regression model was used to calculate treatment outcomes for risk factors, and hazard ratios (HR) were calculated with $95 \%$ confidence interval $(95 \% \mathrm{Cl})$. All the tests were two-sided. Statistical significance was defined as $p<0.05$. Am SPSS25 (IBM, Armonk, NY, USA) statistical package was used.

\section{Results}

\section{Demographics}

Our study included 71 patients with acute leukemia, 43 boys and 28 girls with a median age of 9 (range 1-19.7) 
Table I. Patient characteristics

\begin{tabular}{|c|c|c|c|c|}
\hline Characteristics & Total [\%] & HCT $(n=34)$ & Non-HCT $(n=37)$ & $p$ \\
\hline \multicolumn{5}{|l|}{ Age (years) } \\
\hline Median, range [years] & $9.4(1.1-19.7)$ & $11.2(2.5-19.7)$ & $6.6(1.1-19.7)$ & \\
\hline$<10$ vs. $>10$ & $36(50.7): 35(49.3)$ & $13(38.2): 21(61.8)$ & 23 (62.2):14 (37.8) & 0.205 \\
\hline \multicolumn{5}{|l|}{ Gender } \\
\hline Male:female & $43(60.6): 28(39.4)$ & 23 (67.6):11 (32.4) & 20 (54.1):17 (45.9) & 0.245 \\
\hline \multicolumn{5}{|l|}{ Type of leukemia } \\
\hline ALL:AML & 54 (76.1):17 (23.9) & 18 (52.9):16 (47.1) & 36 (97.3):1 (2.7\%) & $<0.001$ \\
\hline Ferritin $[\mu \mathrm{g} / \mathrm{L}]$ & $461(4-8,500)$ & $1,060(14-8,500)$ & $284(15-2,110)$ & 0.002 \\
\hline ALT $[\mathrm{U} / \mathrm{mL}]$ & $20(6-1,172)$ & $33(9-769)$ & $14(6-1,172)$ & $<0.001$ \\
\hline AST $[\mathrm{U} / \mathrm{mL}]$ & $30(11-554)$ & $40(13-415)$ & $26(11-554)$ & 0.054 \\
\hline $\mathrm{CRP}[\mathrm{mg} / \mathrm{mL}]$ & $7(<5-374)$ & $10(<5-146)$ & $5(<5-374)$ & 0.215 \\
\hline $\mathrm{LDH}[\mathrm{U} / \mathrm{mL}]$ & $297(5-4,705)$ & 341 (113-2,815) & $5(257-4,705)$ & 0.473 \\
\hline
\end{tabular}

ALL - acute lymphoblastic leukemia; AML - acute myeloblastic leukemia; ALT - alanine aminotransferase; AST - aspartate aminotransferase; CRP - C-reactive protein; LDH - lactate dehydrogenase

years. The primary disease in these patients was ALL in 54, and AML in 17 (Table I). The total number of patients who underwent HCT was 34, comprising 32 allo-HCT and two auto-HCT. In 19 patients a MUD, and in 13 a matched sibling donor (MSD) transplant was performed. In one patient, auto-HCT was followed by allo-HCT; this patient was categorised as allo-HCT. The stem cell source for HCT was peripheral blood (19 patients) and bone marrow (15 patients).

\section{Ferritin concentration}

The median value of highest serum ferritin concentrations was 2,307 $\mu \mathrm{g} / \mathrm{L}$ (range: $33-8,500 \mu \mathrm{g} / \mathrm{L}$ ) and $708.44 \mu \mathrm{g} / \mathrm{L}$ (range: $14-7,440 \mu \mathrm{g} / \mathrm{L}$ ) in patients with $\mathrm{AML}$ and $\mathrm{ALL}$, respectively. In 37/71 patients, serum ferritin was $>1,000$ $\mu \mathrm{g} / \mathrm{L}$. Ferritin serum concentration correlated with ALT activity (Spearman's rho coefficient 0.41; $p=0.001$ ), and CRP concentration (rho 0.32; $p=0.012$ ), but not with AST activity or LDH concentration.

\section{Survival of patients}

Overall, 52 (73\%) patients were alive at the end of the study in 2020. Mean survival was 9.0 years $(95 \% \mathrm{Cl}=7.8-10.1)$. Probability of overall survival (pOS) of all patients at 5 years was $0.79 \pm 0.05$, and at 10 years it was pOS $=0.63$ \pm 0.10 ; the 5 -year EFS was $0.70 \pm 0.06$, and the 5 -year RI was $0.19 \pm 0.05$.

Splitting the analysis into subgroups with respect to the highest serum ferritin concentrations, the values of probability of OS, EFS and RI are set out in Table II. Patients with a higher ferritin concentration, regardless of its cut-off value, had worse overall survival and a higher incidence of relapses.
Table II. 5-year treatment outcomes with respect to serum ferritin concentration

\begin{tabular}{|c|c|c|c|c|}
\hline $\begin{array}{l}\text { Ferritin } \\
\text { cut-off } \\
\text { concen- } \\
\text { tration } \\
{[\mu \mathrm{g} / \mathrm{L}]}\end{array}$ & $\begin{array}{l}\mathrm{Pa}- \\
\text { tients }\end{array}$ & os & EFS & RI \\
\hline \multicolumn{5}{|l|}{$\begin{array}{l}\text { Ferritin } \\
500\end{array}$} \\
\hline$<500$ & 36 & $0.89 \pm 0.05$ & $0.86 \pm 0.06$ & $0.06 \pm 0.04$ \\
\hline$\geq 500$ & 35 & $0.68 \pm 0.08$ & $0.52 \pm 0.09$ & $0.35 \pm 0.09$ \\
\hline$p$-value & & 0.008 & 0.003 & 0.006 \\
\hline $\begin{array}{l}\text { Ferritin } \\
1,000\end{array}$ & & & & \\
\hline$<1,000$ & 49 & $0.90 \pm 0.04$ & $0.86 \pm 0.05$ & $0.09 \pm 0.04$ \\
\hline$\geq 1,000$ & 22 & $0.55 \pm 0.11$ & $0.32 \pm 0.10$ & $0.52 \pm 0.13$ \\
\hline$p$-value & & $<0.001$ & $<0.001$ & $<0.001$ \\
\hline \multicolumn{5}{|l|}{$\begin{array}{l}\text { Ferritin } \\
1,500\end{array}$} \\
\hline$<1,500$ & 54 & $0.85 \pm 0.05$ & $0.82 \pm 0.05$ & $0.12 \pm 0.04$ \\
\hline$\geq 1,500$ & 17 & $0.59 \pm 0.12$ & $0.31 \pm 0.12$ & $0.51 \pm 0.15$ \\
\hline$p$-value & & $<0.001$ & $<0.001$ & $<0.001$ \\
\hline \multicolumn{5}{|l|}{$\begin{array}{l}\text { Ferritin } \\
2,000\end{array}$} \\
\hline$<2,000$ & 58 & $0.83 \pm 0.05$ & $0.79 \pm 0.05$ & $0.13 \pm 0.04$ \\
\hline$\geq 2,000$ & 13 & $0.62 \pm 0.14$ & $0.25 \pm 0.13$ & $0.59 \pm 0.185$ \\
\hline$p$-value & & 0.001 & $<0.001$ & $<0.001$ \\
\hline Total & 71 & $0.79 \pm 0.05$ & $0.70 \pm 0.06$ & $0.19 \pm 0.05$ \\
\hline
\end{tabular}

OS - overall survival; EFS - event-free survival; RI - relapse incidence 


\section{Long-term outcomes and differences between HCT and non-HCT patients}

Patients undergoing HCT ( $n=34)$ vs. non-HCT $(n=37)$ had significant differences in long-term outcomes, although in both groups those with a higher ferritin concentration had worse survival. The outcomes for a ferritin concentration threshold value of $1,000 \mu \mathrm{g} / \mathrm{L}$ are shown (Figure $1 \mathrm{~A}-\mathrm{I}$ ). The OS values for non-HCT patients were insignificant compared to those with higher vs. lower ferritin (Figure 1B), but EFS values were significantly lower for those with high ferritin (Figure 1E). This was caused by the higher relapse incidence (Figure 1H). For HCT patients, all outcomes were significantly worse in patients with a high ferritin concentration (Figure 1C, F, I).

\section{Risk factor analysis}

We conducted univariate analysis of factors contributing to overall survival including the following parameters: age of patient ( $<10$ vs. $>10$ years), primary diagnosis (ALL vs. $\mathrm{AML}$ ), ferritin serum concentration ( $<1,000 \mathrm{vs.}>1,000 \mu \mathrm{g} /$ $/ \mathrm{L}$ ), and HCT treatment (non-HCT vs. HCT) (Table III). Adverse risk factors with a $p<0.1$ value were included into multivariate analysis: diagnosis of $\mathrm{AML}$, ferritin concentration $>1,000 \mu \mathrm{g} / \mathrm{L}$, and treatment with $\mathrm{HCT}$. The only significant risk factor in multivariate analysis was ferritin concentration $>1,000 \mu \mathrm{g} / \mathrm{L}$, with a 7.1-fold hazard risk for death. Analogically, ferritin concentration $>1,000 \mu \mathrm{g} /$ /L was the only significant risk factor for EFS and RI with a 4.3-fold and a 6.9-fold hazard risk, respectively, for adverse events and leukemic relapse (Tables IV and V).

\section{Discussion}

Our analysis shows that iron overload is often observed in paediatric patients with acute leukemia who are undergoing intensive chemotherapy with or without HCT. Furthermore, we have shown an adverse prognostic value of ferritin serum concentration. This parameter can be used as a marker negatively influencing overall survival, EFS and relapse incidence in children after treatment for acute leukemia, particularly those undergoing HCT. Previous data has confirmed the predictive power of serum ferritin concentration for survival after allo-HCT and showed that elevated ferritin is associated with an increased risk of relapse [10].

Univariate and multivariate analysis showed that high ferritin serum concentrations were correlated with

Table III. Univariate and multivariate risk factors analysis for overall survival (OS)

\begin{tabular}{|c|c|c|c|c|c|c|}
\hline \multirow[t]{2}{*}{ Parameter } & \multirow[t]{2}{*}{ Characteristics } & \multirow[t]{2}{*}{ 5-year OS } & \multicolumn{2}{|c|}{ Univariate analysis } & \multicolumn{2}{|c|}{ Multivariate analysis } \\
\hline & & & HR $(95 \% \mathrm{Cl})$ & $p$ & HR (95\%Cl) & $p$ \\
\hline \multirow[t]{2}{*}{ Age } & $<10$ years & $0.82 \pm 0.06$ & 1 & 0.339 & - & - \\
\hline & $>10$ years & $0.75 \pm 0.08$ & $1.6(0.7-3.9)$ & & - & \\
\hline \multirow[t]{2}{*}{ Diagnosis } & ALL & $0.83 \pm 0.05$ & 1 & 0.076 & 1 & 0.762 \\
\hline & AML & $0.65 \pm 0.12$ & $2.3(0.9-5.7)$ & & $1.2(0.4-3.1)$ & \\
\hline \multirow[t]{2}{*}{ Ferritin } & $<1,000 \mu \mathrm{g} / \mathrm{L}$ & $0.90 \pm 0.04$ & 1 & $<0.001$ & 1 & $<0.001$ \\
\hline & $>1,000 \mu \mathrm{g} / \mathrm{L}$ & $0.55 \pm 0.11$ & $6.8(2.8-20)$ & & $7.1(2.6-20)$ & \\
\hline \multirow[t]{2}{*}{ Treatment } & Non-HCT & $0.92 \pm 0.05$ & 1 & 0.009 & 1 & 0.165 \\
\hline & HCT & $0.65 \pm 0.08$ & $5.5(1.6-18)$ & & $2.4(0.7-10)$ & \\
\hline
\end{tabular}

$\mathrm{HR}$ - hazard ratio; $95 \% \mathrm{Cl}$ - 95\% confidence interval; ALL - acute lymphoblastic leukemia; AML - acute myeloblastic leukemia; HCT - haematopoietic cell transplantation

Table IV. Univariate and multivariate risk factors analysis for event-free survival (EFS)

\begin{tabular}{|c|c|c|c|c|c|c|}
\hline \multirow[t]{2}{*}{ Parameter } & \multirow[t]{2}{*}{ Characteristics } & \multirow[t]{2}{*}{ 5-year EFS } & \multicolumn{2}{|c|}{ Univariate analysis } & \multicolumn{2}{|c|}{ Multivariate analysis } \\
\hline & & & HR $(95 \% \mathrm{Cl})$ & $p$ & HR $(95 \% \mathrm{Cl})$ & $p$ \\
\hline \multirow[t]{2}{*}{ Age } & $<10$ years & $0.79 \pm 0.07$ & 1 & \multirow[t]{2}{*}{0.110} & - & \multirow[t]{2}{*}{-} \\
\hline & $>10$ years & $0.58 \pm 0.09$ & $2.0(0.8-4.1)$ & & - & \\
\hline \multirow[t]{2}{*}{ Diagnosis } & ALL & $0.77 \pm 0.06$ & 1 & \multirow[t]{2}{*}{0.044} & 1 & \multirow[t]{2}{*}{0.753} \\
\hline & AML & $0.47 \pm 0.12$ & $2.4(1.1-5.5)$ & & $1.3(0.4-2.8)$ & \\
\hline \multirow[t]{2}{*}{ Ferritin } & $<1,000 \mu \mathrm{g} / \mathrm{L}$ & $0.86 \pm 0.05$ & 1 & \multirow[t]{2}{*}{$<0.001$} & 1 & \multirow[t]{2}{*}{0.003} \\
\hline & $>1,000 \mu \mathrm{g} / \mathrm{L}$ & $0.32 \pm 0.10$ & $6.8(2.8-16)$ & & $4.3(1.6-12)$ & \\
\hline \multirow[t]{2}{*}{ Treatment } & Non-HCT & $0.89 \pm 0.05$ & 1 & \multirow[t]{2}{*}{0.002} & 1 & \multirow[t]{2}{*}{0.111} \\
\hline & HCT & $0.48 \pm 0.09$ & $4.9(1.9-13)$ & & $2.5(0.8-7.3)$ & \\
\hline
\end{tabular}

HR - hazard ratio; $95 \% \mathrm{Cl}$ - 95\% confidence interval; ALL - acute lymphoblastic leukemia; AML - acute myeloblastic leukemia; HCT - haematopoietic cell transplantation 


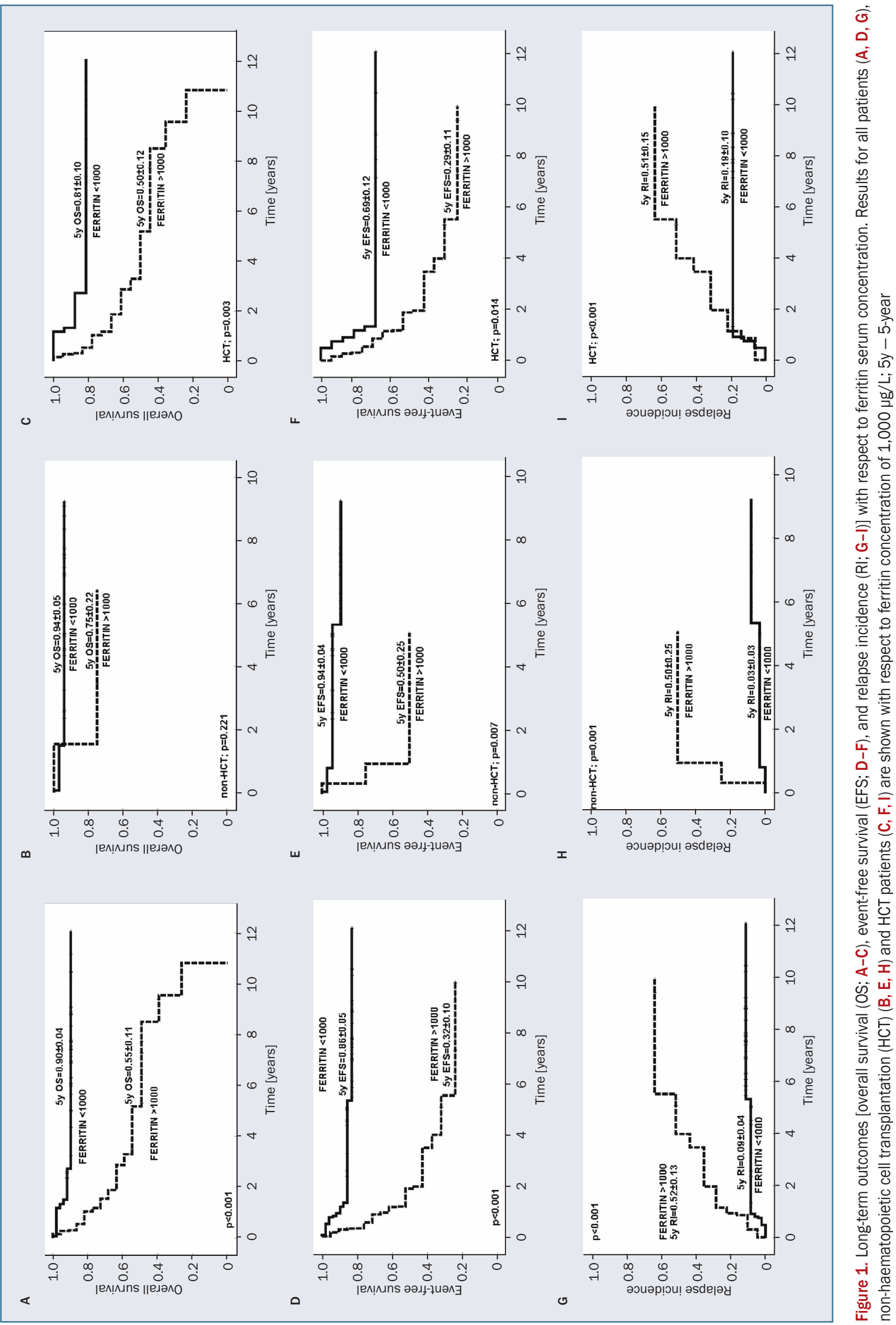


Table V. Univariate and multivariate risk factors analysis for relapse incidence

\begin{tabular}{|c|c|c|c|c|c|c|}
\hline \multirow[t]{2}{*}{ Parameter } & \multirow[t]{2}{*}{ Characteristics } & \multirow[t]{2}{*}{ 5-year RI } & \multicolumn{2}{|c|}{ Univariate analysis } & \multicolumn{2}{|c|}{ Multivariate analysis } \\
\hline & & & HR $(95 \% \mathrm{Cl})$ & $p$ & HR $(95 \% \mathrm{Cl})$ & $p$ \\
\hline \multirow[t]{2}{*}{ Age } & $<10$ years & $0.11 \pm 0.05$ & 1 & 0.174 & - & - \\
\hline & $>10$ years & $0.29 \pm 0.09$ & $2.1(0.7-5.9)$ & & - & \\
\hline \multirow[t]{2}{*}{ Diagnosis } & ALL & $0.14 \pm 0.05$ & 1 & 0.188 & - & - \\
\hline & AML & $0.37 \pm 0.13$ & $2.1(0.7-6.2)$ & & - & \\
\hline \multirow[t]{2}{*}{ Ferritin } & $<1,000 \mu \mathrm{g} / \mathrm{L}$ & $0.09 \pm 0.04$ & 1 & $<0.001$ & 1 & $<0.001$ \\
\hline & $>1,000 \mu \mathrm{g} / \mathrm{L}$ & $0.52 \pm 0.13$ & $6.7(2.2-21)$ & & $6.9(2.3-21)$ & \\
\hline \multirow[t]{2}{*}{ Treatment } & Non-HCT & $0.08 \pm 0.05$ & 1 & 0.039 & 1 & 0.536 \\
\hline & HCT & $0.33 \pm 0.09$ & $3.1(1.1-10)$ & & $1.6(0.4-5.9)$ & \\
\hline
\end{tabular}

$\mathrm{HR}$ - hazard ratio; $95 \% \mathrm{Cl}$ - 95\% confidence interval; ALL - acute lymphoblastic leukemia; AML - acute myeloblastic leukemia; HCT - haematopoietic cell transplantation

decreased survival. This finding aligns with previous data suggesting iron overload to be strongly correlated with a poor prognosis in patients with MDS or after HCT [12]. Data on children undergoing non-HCT treatment for leukemia and other types of malignancy is inconsistent, with iron overload rates ranging from $24-90 \%$ of children (according to [13]), and the clinical consequences of iron overload with respect to risk groups require additional research. As yet, there are no clear guidelines in terms of recommendations for iron overload screening.

Our study has several limitations. It was a retrospective study, meaning that other possible factors influencing iron metabolism could not be taken into account [14]. Also, the impact of disease stage and other possible therapy complications [15-19] were not analysed. The validity of the assessment of ferritin as an indicator related to the clinical course of the disease after treatment in paediatric leukemia is debatable, because serum ferritin might normalise during follow-up in some children [20]. Another concern is the measurement of parameters in different time intervals of blood samples. The number of administered transfusions also was not taken into consideration. Our group of patients was heterogeneous in terms of disease stage and donor type.

Based on our results, we propose the monitoring of ferritin and iron concentrations in all patients with acute leukemia, especially those after the consolidation phase of chemotherapy and those undergoing HCT. Ferritin level $>1,000 \mu \mathrm{g} / \mathrm{L}$ should be taken into account as a significant prognostic factor of death.

\section{Conclusion}

In conclusion, a high ferritin concentration is an adverse prognostic factor for overall survival and event-free survival, and contributes to a higher relapse incidence in children after treatment for acute lymphoblastic or myeloblastic leukemia.

\section{Authors' contributions}

$J S, M Ł$ - study design and manuscript writing; MŁ, RD, KC, JS - collection and analysis of data. All authors - critical review and final approval.

\section{Conflict of interest}

None.

\section{Financial support \\ None.}

\section{Ethics}

The work described in this article has been carried out in accordance with The Code of Ethics of the World Medical Association (Declaration of Helsinki) for experiments involving humans; EU Directive 2010/63/EU for animal experiments; and Uniform requirements for manuscripts submitted to biomedical journals.

\section{References}

1. Pui $\mathrm{CH}$, Yang J, Bhakta N, et al. Global efforts toward the cure of childhood acute lymphoblastic leukaemia. Lancet Child Adolesc Health. 2018; 2(6): 440-454, doi: 10.1016/s2352-4642(18)30066-x.

2. Demidowicz $E$, Pogorzala $M$, Łęcka $M$, et al. Outcome of pediatric acute lymphoblastic leukemia: sixty years of progress. Anticancer Res. 2019; 39(9): 5203-5207, doi: 10.21873/anticanres.13717, indexed in Pubmed: 31519634.

3. Balwierz W, Pawinska-Wasikowska K, Klekawka T, et al. Development of treatment and clinical results in childhood acute myeloid leukemia in Poland. Memo. 2012; 6(1): 54-62, doi: 10.1007/s12254-0120061-9, indexed in Pubmed: 23565126.

4. Meyer SC, O'Meara A, Buser A, et al. Prognostic impact of posttransplantation iron overload after allogeneic stem cell transplantation. Biol Blood Marrow Transplant. 2013; 19(3): 440-444, doi: 10.1016/j. bbmt.2012.10.012, indexed in Pubmed: 23089566.

5. Bernaudin F, Verlhac S, Latour RP, et al. Association of matched sibling donor hematopoietic stem cell transplantation with transcranial Doppler velocities in children with sickle cell anemia. JAMA. 2019; 321(3): 266-276,, doi: 10.1001/jama.2018.20059, indexed in Pubmed: 30667500. 
6. Halyabar 0, Chang M, Schoettler M, et al. Calm in the midst of cytokine storm: a collaborative approach to the diagnosis and treatment of hemophagocytic lymphohistiocytosis and macrophage activation syndrome. Pediatr Rheumatol Online J. 2019; 17(1): 7, doi: 10.1186/ /s12969-019-0309-6, indexed in Pubmed: 30764840.

7. Uppuluri R, Swaminathan VV, Ramanan KM, et al. Haploidentical stem cell transplantation with post-transplant cyclophosphamide in fanconi anemia: improving outcomes with improved supportive care in India. Biol Blood Marrow Transplant. 2020; 26(12): 2292-2298, doi: 10.1016/j.bbmt.2020.08.019, indexed in Pubmed: 32835780.

8. Morgenstern DA, Pötschger U, Moreno L, et al. Risk stratification of high-risk metastatic neuroblastoma: a report from the HR-NBL-1/ /SIOPEN study. Pediatr Blood Cancer. 2018; 65(11): e27363, doi: 10.1002/pbc.27363, indexed in Pubmed: 30015396.

9. Majhail NS, Lazarus HM, Burns $\sqcup$. Iron overload in hematopoietic cell transplantation. Bone Marrow Transplant. 2008; 41(12): 997-1003, doi: 10.1038/bmt.2008.99, indexed in Pubmed: 18438425.

10. Bazuave GN, Buser A, Gerull S, et al. Prognostic impact of iron parameters in patients undergoing allo-SCT. Bone Marrow Transplant. 2011; 47(1): 60-64, doi: 10.1038/bmt.2011.13, indexed in Pubmed: 21399668.

11. Bennett TD, Hayward KN, Farris RWD, et al. Very high serum ferritin levels are associated with increased mortality and critical care in pediatric patients. Pediatr Crit Care Med. 2011; 12(6): e233-e236, doi: 10.1097/pcc.0b013e31820abca8, indexed in Pubmed: 21263363.

12. Kikuchi S, Kobune M, lyama S, et al. Prognostic significance of serum ferritin level at diagnosis in myelodysplastic syndrome. Int J Hematol. 2012; 95(5): 527-534, doi: 10.1007/s12185-012-1048-3, indexed in Pubmed: 22407873.
13. Landier W, Armenian SH, Lee J, et al. Yield of screening for long-term complications using the children's oncology group long-term follow-up guidelines. J Clin Oncol. 2012; 30(35): 4401-4408, doi: 10.1200/ /JC0.2012.43.4951, indexed in Pubmed: 23091100.

14. Michalak S. Perspectives for the therapy of anemia of chronic diseases. Acta Haematol Pol. 2020; 51(3): 125-132, doi: 10.2478/ahp2020-0024.

15. Styczynski J. Infectious complications in children and adults with hematological malignancies. Acta Haematol Pol. 2019; 50(3): 167-173, doi: 10.2478/ahp-2019-0027.

16. Demidowicz E, Bartoszewicz N, Czyżewski K, et al. Acute non-hematological toxicity of intensive chemotherapy of acute lymphoblastic leukemia in children. Acta Haematol Pol. 2020; 51(3): 164-171, doi: 10.2478/ahp-2020-0029.

17. Styczyński J. ABC of viral infections in hematology: focus on herpesviruses. Acta Haematol Pol. 2019; 50(3): 159-166, doi: 10.2478/ /ahp-2019-0026.

18. Bartoszewicz N, Czyżewski K, Dębski R, et al. Efficacy of keratinocyte growth factor in prevention of oral mucositis in children undergoing allogeneic hematopoietic cell transplantation. Acta Haematol Pol. 2020; 51(3): 172-178, doi: 10.2478/ahp-2020-0030.

19. Styczyński J. Prophylaxis vs preemptive therapy in prevention of CMV infection: new insight on prophylactic strategy after allogeneic hematopoietic cell transplantation. Acta Haematol Pol. 2020; 51(1): 17-23, doi: 10.2478/ahp-2020-0005.

20. Brierley CK, Iniesta RR, Storrar N, et al. Hyperferritinemia in pediatric acute lymphoblastic leukemia. J Pediatr Hematol Oncol. 2017; 39(3): 238, doi: 10.1097/mph.00000000000000712, indexed in Pubmed: 27879547. 